\title{
Arab Spring as a sign of continuity and change
}

In the editorial note of the first issue of Regions $\mathcal{E}$ Cohesion, we directly asked ourselves and our readers: What role do people play in regional integration processes? Regions have, indeed, developed in different ways and for different reasons. One of the main questions behind the mission of this journal asks: Are territories serving their citizens, or do citizens serve the needs of expanding territories and interconnected markets?

The intellectual contributions published in Regions \& Cohesion focus on the social and environmental impacts of regional integration, with particular attention paid to social cohesion. Cohesion policies, of course, have been established and implemented by different regional organizations, generally with limited impacts.

Many observers of region-building have argued that regional integration processes need to include greater social participation and grassroots mobilization. Numerous discussions in Europe, Latin America, and Africa have asked how regional governance can foster such democratic participation. Few (dare we say nobody) expected, however, that North Africa and the Middle East would take the lead in people-centered region-building.

"Special issues" receive this title because of their focus on specific themes. In this case, we consider this thematic issue to be special because of the extraordinary events that occurred during what is known as "Arab Spring." While scientific and political debates surround explanations for and meanings of the historic events that have occurred since the spring of 2011 in the Arab world, the spontaneous and contagious natures of different sociopolitical mobilizations created a people-focused process of regional integration that gave hope to some and alarmed others. Protest was met by repression. In some cases, repression was then met with violence, and what started as social movements became full-fledged civil wars. Has the Arab Spring improved the lives of those living in the countries that were touched by this phenomenon? Of course, only the future holds the answer to this question. However, the Arab Spring revolts were not scripted by domestic or international leaders, and for this reason, they are surely of special significance for the mission of Regions $\mathcal{E}$ Cohesion. Not addressing them would be a tremendous omission. We thank our colleague Gilberto Conde Zambada for organizing this special issue of the journal. 
Since Heraclitus (c.535-475 в.с.) first stated "There is nothing permanent except change," we have reflected on the role of change in our lives. We have viewed change as "the absence of permanence and the importance of continuity" (Buddhism). Modern ideologues, such as Mahatma Gandhi, have identified the need to foster change from below ("Be the change you want to see in the world.") We do believe that the continuity of a society must not be interrupted and, therefore, we need not be afraid of change. However, the demands for continuity are not constant, and, therefore, we should humbly recognize them when they appear and support those who aim to establish better, plural, and democratic horizons.

The editors 